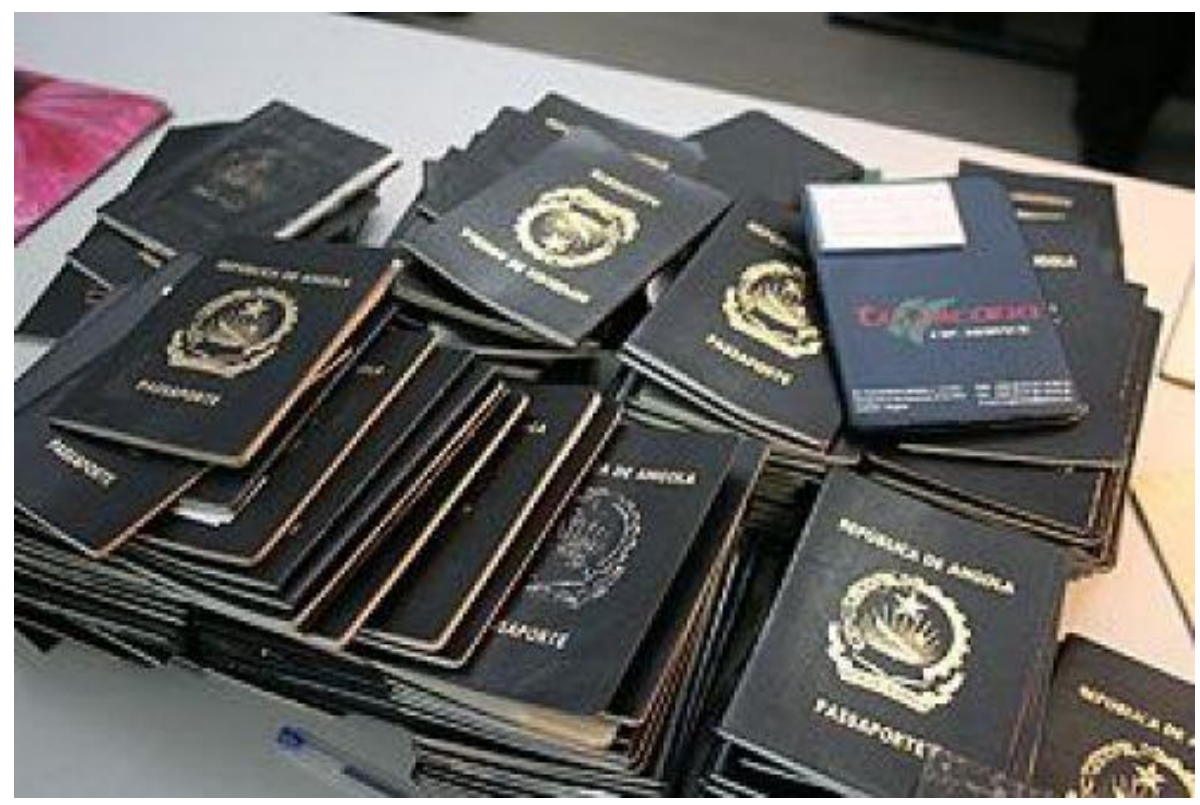

\title{
O estigma da ameaça ao emprego pelos periféricos na periferia: crise e imigração no Brasil
}

The stigma of the threat to employment by peripheral on the periphery: crisis and immigration in Brazil

Patricia Villen $^{1}$

Resumo: Discute-se as razões pelas quais, mesmo com o percentual baixíssimo de população estrangeira atualmente no Brasil, num contexto de crise - com bruscos aumentos das taxas de desemprego - a figura do imigrante e do refugiado continua, como no passado, a representar um estigma da ameaça ao emprego. A especial ênfase dada à dimensão do trabalho elucida questões de fundo para se compreender as atuais manifestações de violência, racismo, xenofobia contra esses grupos. Procurou-se trazer em discussão as características históricas da base social da imigração de proveniência de países periféricos para o Brasil, sua ligação com a manifestação mais ampla desses fluxos em escala internacional, mostrando em que medida o país entra, hoje, como destino desses movimentos migratórios e as problemáticas derivadas.

Palavras-chave: imigração, refúgio, trabalho, crise

Abstract: This article discuss the reasons why, even with the very low percentage of foreign population today in Brazil, in the current crisis - with sharp increases in unemployment - the figure of the immigrant and refugee continues, as in the past, representing the stigma of the threat to employment. The special emphasis on the dimension of work elucidates fundamental issues for understanding the current manifestations of violence, racism, xenophobia against these groups. It aims to bring into discussion the historical characteristics of the social basis of immigration from peripheral countries to Brazil, its connection with the wider manifestation of these flows on the international scale, in order to show to what extent the country enters as a migration destination today and the questions implied.

Keywords: immigration, refuge, work, crisis

\footnotetext{
${ }^{1}$ Doutora em Sociologia pelo Instituto de Filosofia e Ciências Humanas da Universidade Estadual de Campinas e pós-doutoranda no Observatório das Migrações em São Paulo, Núcleo de Estudos de População Elza Berquó, Av. Albert Einstein, 1300 - Cidade Universitária, Campinas - SP. Email: villenpatricia@gmail.com.
} 
Como entender as atuais manifestações de violência, racismo, xenofobia que têm como alvo os imigrantes e refugiados - principalmente os não-brancos provenientes de países periféricos - sem considerar as dinâmicas de funcionamento do mercado de trabalho?

Segundo Sayad (1998), é nos momentos de crise - já anunciada como uma certeza histórica para os próximos anos no Brasil - que a verdade da imigração se revela. A frase "vocês roubam nossos empregos!", pronunciada pelos responsáveis dos tiros disparados contra seis haitianos que se encontravam em São Paulo, no dia 8 de agosto de 2015, em frente à Igreja da $\mathrm{Paz}^{2}$ - espaço representativo, na atualidade, da busca e da necessidade extrema de trabalhar por parte de imigrantes e refugiados recém-chegados nessa cidade é bastante elucidativa dos limites de uma aproximação da problemática que não se pergunte sobre essa ligação.

Se o mercado de trabalho é um termômetro para se compreender o aumento e a diminuição das entradas de imigrantes e refugiados em determinados contextos econômicos e políticos da história do país, também oferece parâmetros para se analisar as oscilações desses diferentes tipos de hostilidade contra o "estrangeiro".

A convivência entre nacionais e "estrangeiros", tanto conflituosa como solidária, é parte presente da história da imigração no Brasil, notadamente para aqueles pertencentes à classe trabalhadora, em geral, com maior presença numérica nos diferentes tipos de movimentos internacionais de populações. Do mesmo modo, a estratégica construção de "falsos antagonismos" (BASSO, 2015) entre essas categorias, tão disseminados nos tempos atuais, não é uma novidade num país com longa tradição de imigração.

Em especial, os períodos históricos marcados por crises de ordem econômica e política na conjuntura nacional e internacional explicam a funcionalidade da construção de um universo simbólico que coloca o estrangeiro como "concorrente", como "bode expiatório" do mal estar socioeconômico, senão como "potencial inimigo" da nação (BASSO, 2010).

No Brasil, a década de 1930 representa um laboratório importante para análise dessas questões. O primeiro "fechamento" das fronteiras foi funcionalmente justificado

\footnotetext{
${ }^{2}$ Embora tenham sempre existido, não há dúvida de que os diferentes tipos de agressões a imigrantes e refugiados se intensificaram sobremaneira no ano de 2015, com o aumento das taxas de desemprego no país (pelos dados da Pesquisa de Emprego e Desemprego do Seade/Dieese, a taxa de desemprego na Região Metropolitana de São Paulo subiu ininterruptamente durante todo o ano, atingindo 13,7\% em julho de 2015). No caso citado, a despeito de as balas terem sido de "chumbinho", não deixaram de ferir e, principalmente, ameaçar pelo medo essa base social da imigração no Brasil contemporâneo.
} 
pelo governo de Getúlio Vargas para agir nas supostas causas do "desemprego", do "aumento da desordem econômica" e da "insegurança social" (decreto 19.498/1930; CARNEIRO et al., 2010; GERALDO, 2007). Nesse período, além da obrigatoriedade da cota de 2/3 de brasileiros natos nos postos de trabalho ${ }^{3}$, o recorte de classe aparecia como um critério seletivo (dos fluxos de entrada) explícito em lei, já que o estrangeiro impedido de entrar no país era aquele que vinha porque precisava trabalhar, aquele que viajava na terceira classe dos navios, não aquele que podia comprovar "posses" ou "renda" (decreto 19.482/1930). Na contracorrente do que, até então, caracterizava a história da imigração no país, impedia-se a entrada de "trabalhadores livres" - que antes vinham em grandes contingentes, seja "voluntariamente", seja pelo recrutamento, incentivo e financiamento público e privado da imigração para a formação do mercado de trabalho assalariado.

Nas décadas posteriores, a despeito de a porcentagem da população estrangeira ter sofrido uma queda significativa - de 5,11\% no Censo Demográfico de $1920^{4}$ a 0,77\% naquele de 1980 (BASSANEZI, 1995) -, a mesma preocupação de "proteger" o trabalhador nacional não deixou de se fazer presente. Neste mesmo ano, a equação pretensamente neutra da imigração/qualificação-especialização vem inaugurada com a Lei 68.815/1980, o Estatuto do Estrangeiro ${ }^{5}$. A partir de então, o imigrante que conseguiria permissão formal para trabalhar no Brasil seria somente aquele que, comprovadamente, não "ameaçasse" o trabalhador nacional, ou seja, comprovasse ter um diferencial não encontrado no país ${ }^{6}$.

\footnotetext{
${ }^{3}$ A lei dos $2 / 3$ foi instituída pelo Decreto 19.482/1930, art. $3^{\circ}$ : “todos os indivíduos, empresas, associações e firmas comerciais, que explorem, ou não, concessões do Governo Federal ou dos Governos Estaduais e municipais, ou que, com esses Governos contratem quaisquer fornecimentos, serviços ou obras, ficam obrigadas a demonstrar perante o Ministério do Trabalho, Indústria e Comércio, dentro do prazo de noventa dias, contados da data de publicação do presente decreto, que ocupam, entre os seus empregados, de todas as categorias, dois terços, pelo menos, de brasileiros natos. Parágrafo único. Somente na falta de brasileiros natos e para serviços rigorosamente técnicos, a juízo do Ministério do Trabalho, Indústria e Comércio, poderá ser alterada aquela proporção, admitindo-se, neste caso, brasileiros naturalizados, em primeiro lugar, e, depois, os estrangeiros". É válido lembrar o que Geraldo (2007: 68) destacou: "[a] lei dos dois terços encontrou, no entanto, uma série de obstáculos a partir de sua promulgação. Logo que anunciada, a lei enfrentou a oposição tanto dos trabalhadores quanto das entidades patronais".

${ }^{4}$ Ressalta-se que o Censo Demográfico não foi realizado na década de 1930, portanto, utilizou-se como parâmetro o censo de 1920.

${ }^{5}$ Esta lei regulamenta a entrada e a permanência de imigrantes no país até nos dias atuais (2015).

${ }^{6} \mathrm{O}$ resultado histórico dessa política foi a convivência da entrada de restritos fluxos dentro do circuito legalizado da imigração por motivo de trabalho - selecionados para a inserção laboral em setores estratégicos, geralmente ligados à entrada de capitais estrangeiros no país, ou com escassez de profissionais - com um universo social muito mais amplo de fluxos provenientes de países periféricos, geralmente em condição socioeconômica vulnerável e em situação indocumentada (Villen, 2015). É válido lembrar que esse quadro não se restringe ao contexto brasileiro, mas tem uma amplitude internacional, ou seja, denota o que Dreher (2007) aponta como um padrão neoliberal da migração internacional.
} 
Logo, tratam-se de questões com raízes antigas, mas que, hoje, se manifestam a partir de "outra" base social dos fluxos migratórios, compreendido o refúgio, que é principalmente proveniente de países periféricos, em geral não-branca. Esse perfil sociológico da imigração rediscute, agora no seio das próprias periferias, o que Sayad (1998) chamou de "paradoxos da alteridade", referindo-se às dinâmicas da imigração proveniente de países periféricos naqueles centrais.

$\mathrm{Na}$ atualidade do Brasil, com as taxas de desemprego que se anunciam, de novo, graves para os próximos anos, não serão poucos os desafios colocados pelo contexto de intensificação dos movimentos migratórios internacionais em escala global. Sem dúvida, a figura do imigrante será muito exposta tanto à exploração do seu trabalho, quanto à discriminação, ou mesmo a manifestações de xenofobia.

Nesse sentido, é preciso, antes de tudo, entender as características dessa base sócio-histórica da imigração em sua relação com o trabalho, ou seja, a particularidade da força de trabalho de imigrantes e refugiados provenientes de países periféricos que, por meio dos deslocamentos internacionais, se encontram novamente vivendo e trabalhando num país periférico: daí a denominação periféricos na periferia, que será aprofundada a seguir.

Com esse intuito, serão, na primeira seção, contextualizados os fluxos provenientes das periferias do capitalismo para o Brasil na segunda metade do século XX, com especial atenção às dinâmicas do fenômeno no contexto após a eclosão da crise nos países centrais (2007). Na segunda seção, serão problematizados os fatores que ajudam a entender a condição particular desses imigrantes e sua relação com a inserção em empregos altamente marcados pela precarização. Essas seções trazem elementos para se compreender a denominação sugerida para esses imigrantes e refugiados, qual seja, de periféricos na periferia, bem como para se discutir as características e as problemáticas dessa base social da imigração no Brasil em sua relação com o trabalho, em particular no que se refere ao seu estigma de "ameaça ao emprego".

\section{A mudança dos fluxos internacionais e seu reflexo no Brasil}

Na segunda metade do século XX, em particular depois da crise dos anos 1970, houve grandes transformações nas dinâmicas dos fluxos migratórios internacionais em escala mundial. Com a exceção de algumas regiões do Oriente Médio receptoras desses fluxos, os países da periferia do capitalismo - não mais a Europa - emergem, nesse período, como principais focos dos movimentos populacionais em escala internacional, ou seja, como produtores de emigrantes e refugiados. 
Embora o quadro das diferentes modalidades dos movimentos migratórios seja bastante complexo, no contexto neoliberal, falar de migração internacional e refúgio, hoje mais do que nunca fenômenos imbricados (MACKAY, 2009), significa considerar massas de pessoas, em sua maioria provenientes de países periféricos, que se deslocam principalmente para os países centrais (BASSO, 2003) e, em menor escala, também àqueles que, a despeito de ocuparem uma posição subordinada no mercado mundial, se encontram numa situação um pouco menos dramática, como é o caso do Brasil.

No país, essa realidade social periférica dos fluxos internacionais tem sido silenciada e invisibilizada, desde pelo menos os anos 1960, quando as entradas de coreanos e bolivianos começavam a ganhar corpo. Desde então, as "grandes levas anônimas", expressão de Florestan Fernandes (2008b, p. 157) para se referir à imigração do século XIX e da primeira metade do XX, passam a ser compostas, também no Brasil, por imigrantes e refugiados da periferia do capitalismo (BAENINGER, 1996; MOREIRA, 2012).

Se essa modalidade de imigração forçadamente indocumentada e institucionalmente silenciada antes era composta em sua maioria por essas nacionalidades, no século XXI - em particular após a eclosão da crise nos países centrais (2007), combinada com o recrudescimento das políticas imigratórias nesses territórios (BASSO, 2010) - passa a conjugar uma diversidade de proveniência de fluxos (de imigrantes e refugiados), circunscritos principalmente aos contextos periféricos da América Latina, África e Ásia (BAENINGER, 2013).

Com o fim de expor as linhas gerais desses fluxos na atualidade, que são importantes para se analisar essa base histórica da imigração no Brasil em sua relação com o trabalho, sugere-se uma divisão em dois grupos, segundo os países de proveniência e a modalidade predominantemente indocumentada de entrada no país, apresentados abaixo.

O primeiro grupo refere-se aos fluxos de nacionalidades provenientes do Mercosul (Argentina, Uruguai e Paraguai) e países associados (Bolívia, Colômbia, Chile, Venezuela). Alguns desses fluxos, ganham peso no Brasil principalmente a partir da década de 1970. Por esse motivo, podem ser considerados contínuos, não tendo sido interrompidos nem mesmo no contexto de recessão e crise das décadas de 1980 e 1990.

Como é notório, até há pouco tempo, esses fluxos eram predominantemente de indocumentados. Os direitos conquistados por uma luta antiga dos próprios imigrantes no acordo de residência para cidadãos do Mercosul e países associados - de 2009, porém 
operacionalizado, sobretudo, a partir de 2013 - abrem espaço, gradativamente, à formação de um bloco regional de mercado de trabalho, como já ocorre na União Europeia. Todavia, como esse acordo de residência não é sinônimo de direitos desburocratizados de residência e de trabalho, implicando um regime provisório (sujeito à renovação), muitos imigrantes mercosulinos ainda se encontram em situação indocumentada ou correm o risco de se tornarem indocumentados. É verdade, no entanto, que essa situação indocumentada caminha para incidir com maior peso nos fluxos de imigrantes e solicitantes de refúgio de outros países da América Latina, África e Ásia.

Esses últimos fluxos compõem o segundo grupo, de certa forma mais característico das particularidades do período analisado. A nacionalidade haitiana desponta (depois de 2010, data do terremoto) como principal representante desse grupo (FERNANDES \& CASTRO, 2014). Sem dúvida, esse fluxo é elucidativo de um êxodo muito violento da população haitiana - estimativas apontam cerca de 3 milhões de haitianos vivendo fora do país, numa população de aproximadamente 9 milhões de habitantes (SEGUY, 2014). Até o momento, esses fluxos têm recebido um tratamento especial por parte do governo brasileiro, que concede uma cota muito reduzida de vistos no próprio Haiti, portanto dentro do circuito legalizado. Com relação aos outros milhares de excluídos dessa cota, que só têm a alternativa de entrar de forma indocumentada no Brasil, o Estado, por enquanto, não está se opondo à regularização de caráter emergencial e por "razões humanitárias", pela concessão direta do visto permanente ${ }^{7}$

Esse segundo grupo também é composto por nacionalidades periféricas muito diversificadas da África, Ásia e países da América Latina não membros ou associados ao Mercosul. Parte desses fluxos é composta por solicitantes de refúgio e outra parte por imigrantes que procuram trabalho e melhores condições de vida. Muitas vezes, como fica cada vez mais evidente na atualidade do Brasil e do contexto internacional (MACKAY, 2009), esses dois fluxos estão imbricados.

Mas, em que medida o Brasil pode ser considerado um destino desses fluxos na atualidade?

O Brasil, atualmente, caracteriza-se como um país ao mesmo tempo receptor de imigrantes e solicitantes de refúgio e produtor de emigrantes ${ }^{8}$. Segundo estimativas da

\footnotetext{
${ }^{7}$ Como resultado dessa política, estima-se a presença de 14.000 haitianos regularizados no Brasil e cerca de 50.000 indocumentados.

${ }^{8}$ Em 2013, a Organização Internacional para as Migrações estimava a existência de 3 milhões de nacionais habitando fora do país.
} 
Organização Internacional para as Migrações, foi o principal destino dos fluxos migratórios na América Latina na última década. Contudo, se considerada a média de 10,8\% (ONU, 2013) da população estrangeira nos países centrais, percebe-se que a porcentagem no Brasil, de aproximadamente 0,5\%, é muito inferior. Da mesma forma, essas estatísticas permanecem baixas com relação aos refugiados que estavam no país em 2014 - cerca de oito mil, segundo dados do Alto Comissariado das Nações Unidas para Refugiados (ACNUR, 2014) ${ }^{9}$. Se esse número vem comparado com as estimativas para o mesmo ano referentes à União Europeia (714.300) ou à América do Norte (134.600), percebe-se que o Brasil recebe uma parcela mínima dos fluxos de refugiados (ONU, 2014). Todavia, a análise estatística sobre refúgio desse mesmo órgão aponta o crescimento do fenômeno no país, principalmente nos últimos quatro anos.

Mas, se o percentual dessa população de estrangeiros oficialmente é mais baixo do que aquele de 1980, ou seja, ainda é insignificante para poder significar uma "verdadeira ameaça" ao emprego do trabalhador nacional, por que continua a representar um potencial "roubo" de postos de trabalho?

\section{Os periféricos na periferia}

A maior ameaça simbolizada pela presença desse perfil sociológico da imigração no Brasil é exatamente sua necessidade imediata, extrema e ininterrupta de trabalhar. Do mesmo modo, é verdade, que por serem de proveniência de países periféricos, em geral, não-brancos, compõem uma base social representativa de um novo enquadramento para as dinâmicas de atuação do racismo no Brasil, o que ajuda também a entender a carga de agressividade muitas vezes manifestada por nacionais contra esses imigrantes.

Além de enfrentarem os preconceitos de uma sociedade com herança escravista que, no fundo, ainda associa a imigração com o mesmo referencial racista da "modernização dependente" no passado (FERNANDES, 2008a) - e todos os condicionantes do trabalho dentro de um regime de acumulação flexível, como já mencionado, também se deparam com políticas e leis imigratórias formalmente fechadas.

Com a presença dessa "outra" imigração (muito recorrentemente em situação indocumentada) no país, as mesmas "linhas não expressas da especialização racial”, às

\footnotetext{
${ }^{9} \mathrm{O}$ mesmo documento aponta que neste ano foram analisadas 2.206 solicitações de refúgio, das quais 1.952 foram deferidas, compondo 81 nacionalidades diferentes no país, sendo as mais representativas: colombianos, sírios, angolanos e congoleses.
} 
quais Florestan Fernandes (2008a) se referia - para explicar a posição do negro e de grupos subalternos no mercado de trabalho brasileiro - passam a iluminar o movimento de rebaixamento e exploração da força de trabalho de imigrantes e refugiados provenientes de países periféricos.

Com o fim de se refletir sobre a presença desses imigrantes e refugiados no Brasil, remete-se ao conceito de imigrante utilizado por Sayad (1998), como sinônimo de uma condição social, que chama atenção tanto à sua posição de classe na sociedade de origem, quanto àquela do seu país de origem nas relações internacionais e na divisão internacional do trabalho ${ }^{10}$. Nesse sentido, o imigrante a que se refere o autor é um trabalhador que provém de países "dominados" "11 na hierarquia das relações internacionais.

Para essa parte social, numericamente mais significativa da atualidade do fenômeno no Brasil, a relação entre imigração e trabalho é mediada, de forma inerente, pela urgência no atendimento de necessidades materiais básicas (para si e, muitas vezes, para familiares no país de origem), em muitos casos, determinante da própria sobrevivência. A natureza dessa mediação, está diretamente relacionada com a execução de atividades laborais altamente marcadas por tendências da precarização do trabalho como, por exemplo, no setor têxtil, na construção civil, na indústria de abate de carnes e no serviço doméstico.

Primeiro o trabalho responde ao indispensável de se comer, ter uma moradia, o mínimo para se manter no país, depois, eventualmente, permite, com muitos sacrifícios de jornadas intensas e incessantes de trabalho, a reserva de uma poupança, em quantias pequenas, que geralmente são enviadas por remessas para os familiares no país de origem ou reinvestidas no esforço contínuo para melhorar a estruturação da vida no Brasil. Essa condição de periféricos na periferia agrega, portanto, a dependência absoluta do trabalho com a necessidade imediata e ininterrupta de trabalhar.

\footnotetext{
${ }^{10}$ Sayad lembra que o "imigrante é o duplo do emigrante". Por esse motivo, é importante considerar a "relação dialética que une as duas dimensões do mesmo fenômeno, a emigração e a imigração; ou, em outros termos, como um mesmo conjunto de condições sociais pode engendrar, grosso modo, num dado momento da história do processo (ou da história de um grupo em particular), uma forma particular de emigração, ou seja, uma classe particular de emigrantes [...], sendo que esses emigrantes resultavam num segundo momento numa classe particular de imigrantes e, em seguida, num forma particular de imigração" (SAYAD, 1998, p.18).

${ }^{11}$ Remete-se aqui ao que Sayad considera importante para entender o fenômeno da imigração, ou seja, a atuação do sistema de colonização no passado e seus efeitos e prolongamentos no presente: "A imigração que é produto da colonização ou deriva diretamente dela. A colonização que a imigração prolonga e faz sobreviver de certa forma" (SAYAD, 1998, p. 71).
} 
Sem dúvida, é possível afirmar que a condição desses imigrantes não deixa de manifestar uma continuidade com o mesmo motor que movia as referidas "grandes levas anônimas" do passado para o Brasil, sem ignorar as particularidades e toda complexidade de suas dinâmicas na atualidade, que envolvem todo o globo e características novas em diferentes aspectos (BAENINGER, 2015) - funcionamento das redes, número de países envolvidos, tempo de permanência, particularidades das experiências imigratórias permitidas pelo desenvolvimento dos meios de transporte e das tecnologias de comunicação, modo de operar das políticas imigratórias etc.

Para identificar as características dessa força de trabalho em suas linhas gerais, antes de tudo, é necessário se perguntar em que medida a precariedade pode ser considerada seu diferencial?

Embora haja uma escassez de estudos mais sistemáticos e de bases estatísticas para um melhor entendimento do modo como esses imigrantes são atingidos pelos fatores de precarização, num país com uma reserva abundante de força de trabalho, como o Brasil, é preciso ter cautela ao afirmar que seu traço distintivo, em relação aos nacionais, seja o preenchimento de empregos mais precários.

Na realidade, sua posição ocupada no mercado de trabalho brasileiro é muito semelhante àquela da maioria da população nacional, pois com ela divide os gerais fatores de precarização do trabalho de uma periferia do capitalismo (e.g. ANTUNES, 2014; BRAGA, 2012; KREIN, 2013). Essa condição de classe, em conjunto com sua proveniência periférica, também faz essa categoria partilhar a atuação de um racismo secular que, no que se refere ao funcionamento do mercado de trabalho, como argumentado por Fernandes (2008a), soube se renovar, mesmo sem suas bases legais escravistas $^{12}$.

Talvez a particularidade da força de trabalho dos periféricos na periferia tenda a se revelar na combinação de aspectos ligados à sua própria condição de imigrante (linguística, cultural, de direitos, em alguns casos da falta de apoio de familiares ou redes sociais no Brasil) com todo o processo de imigração imposto, desde a partida, a quem precisa emigrar com meios escassos ou se endividando.

Dessa vulnerabilidade deriva uma maior exposição e disponibilidade (por necessidade) à exploração, no trabalho e em todos os âmbitos da vida social em que sua presença possa se tornar lucrativa - veja-se, por exemplo, os empresários das fronteiras,

${ }^{12} \mathrm{O}$ estudo de Baeninger et. al (2011), realizado a partir de uma pesquisa de campo com bolivianos na cidade de São Paulo, mostra como o racismo também se manifesta pela sua negação. 
as altíssimas taxas para enviar remessas, o preço de aluguéis cobrados de cada imigrante dividindo metros quadrados (muitas vezes insalubres).

A via para chegar e entrar no Brasil já é, de início, muito representativa dessa particularidade e, em geral, não caminha dentro dos circuitos institucionais, com a exceção, como visto acima, aos cidadãos do Mercosul e de países associados (a partir de 2009), aos vistos humanitários concedidos a uma parcela restrita dos fluxos de haitianos e aos casos especiais dos vistos de por casamento e paternidade.

Para muitos desses imigrantes, o modo de entrar no país, diferentemente do que ocorria no passado, é hoje, em grande parte, por uma via indocumentada, que cobra um preço material e psicológico muito alto para emigrar e, em alguns casos, significa até o risco de perder a própria vida, ser extorquido ou sofrer violências, principalmente no caso das mulheres. O deslocamento entre países, em geral, é preparado com muitos sacrifícios, implica renúncias e uma alta dose de coragem, pois sempre exige muito em termos financeiros (com relação às reservas que o imigrante possui ou não possui) e também emocionais.

É necessário precisar que a indocumentação, no que se refere aos efeitos que possui nas relações laborais, não é somente sinônimo de informalidade. No exercício de uma atividade laboral, em termos formais (de direito), tem os mesmos efeitos, porém sua substância vai além dessa esfera, pois carrega um peso a mais de condicionamentos, objetivos e subjetivos, que colocam o imigrante numa situação ainda mais vulnerável do que aquela contida no trabalho informal, com efeitos mais amplos também na vida social.

Para todos os efeitos, a situação indocumentada equivale ao "pesadelo kafkaniano de vias sem saída" que, como esclarece Löwy (2005, p. 202), ficou conhecido pela expressão de situação kafkaniana para descrever "um leque de experiências que vai do absurdo ridículo do funcionamento cotidiano das instituições burocráticas até as manifestações mais mortais do poder administrativo”. Essa situação kafkaniana dos indocumentados tangencia, no mínimo, uma exposição ao sistema de trabalho forçado, fenômeno que atinge também brasileiros (FIGUEIRA et al., 2011), mas, há décadas, está profundamente imbricado com os movimentos migratórios desse perfil de imigrantes veja o caso dos bolivianos na indústria têxtil.

Os elementos trazidos no estudo de Silva (2008), por exemplo, esclarecem um ponto-chave para a compreensão da situação indocumentada e sua funcionalidade laboral: a total dependência do empregador e da sua conduta, tendo em vista que essa "imigração se fundamenta em uma certa economia da palavra baseada na confiança" (SILVA, 2008, 
p. 92) no empregador para determinar os termos da relação empregatícia. Essa condição de fundo é complementada por outros fatores, como a rede de agenciamento envolvendo coiotes e aliciadores ${ }^{13}$; o isolamento forçado do imigrante; o medo de ser denunciado e pego pela polícia ou de perder o emprego e, muitas vezes, o endividamento para conseguir entrar e trabalhar no Brasil.

O autor descreve essa situação indocumentada de trabalho nas oficinas têxteis na cidade de São Paulo, foco de seu estudo realizado na segunda metade da década de 2000, como "fragilizada sem muitas possibilidades de defesa contra a extrema exploração do seu trabalho, sujeitos a multas [do Estado Brasileiro por permanecer ilegalmente no território] e sob constante ameaça de deportação” (SILVA, 2008, p. 92). Segundo relata, essa condição envolve o "controle das condições de vida dos empregados [em particular daqueles que moram nas oficinas]”; o qual muitas vezes é reforçado pelo endividamento do trabalhador que é obrigado a "permanecer nas oficinas enquanto sua dívida não for paga". Todos esses fatores caracterizam a natureza de um trabalho sob "grande pressão do rendimento produtivo": eles "vêm endividados, se não produzem, não podem comer" (op. cit., p. 12, 96 e 97).

Principalmente nos primeiros meses de estadia, quando não possuem redes de apoio no Brasil, são obrigados a recorrer a ajudas de entidades de caráter religioso (Caritas, Pastoral do Imigrante) ou ONGs para conseguirem moradia, assistência social e jurídica, eventualmente a regularização dos documentos. As redes de compatriotas, de outros imigrantes ou mesmo de brasileiros, de fato são vitais como apoio para possibilitar a vinda e a estabilização desses imigrantes, mas também mantêm os limites inerentes à condição de classe - que possui recursos mínimos para ajudar, geralmente dividindo o que já é escasso, ou seja, não é suficiente para garantir a permanência desses imigrantes no país. Ao contrário, o trabalho é determinante nesse sentido.

Para os mais jovens, os meios financeiros escassos e as barreiras de vistos não os impedem de pensar em reemigrar novamente para outro país, atravessando outra barreira nacional. Todavia, na verdade, quem, antes de tudo, possibilita o projeto imigratório é o empregador que encontrará. Antes se trabalha, depois se busca o resto. Por isso, após conseguir entrar no país de destino, o emprego é seu primeiro direcionamento. E quando o alcança, tem que pensar bem para recusar qualquer pedido do empregador, mudar de

\footnotetext{
${ }^{13}$ No caso de bolivianos que trabalham na indústria têxtil, essas redes estão presentes na Bolívia e no Brasil: "há um mercado que explora essa imigração" e "futuros empregadores que financiam a viagem", sendo que as "rotas são alteradas de acordo com a pressão da fiscalização [policial]" (SILVA, 2008, p. 91).
} 
emprego ou correr o risco de ficar impeditivos pequenos intervalos sem trabalhar. Esse imigrante também sabe que, se custa tanto abrir uma porta, ela pode se fechar com uma rapidez espantosa, principalmente, como nos ensina Sayad (1998), nos momentos de crise, quando a verdade da imigração se revela sem nenhum pudor para o imigrante.

Eles sabem que o preço da mobilidade internacional é hoje, no mínimo, mais demorado para se pagar. Também sabem que a imobilidade se impõe durante, pelo menos, os primeiros anos de imigração. Mesmo na idade técnica avançada dos transportes, horas, dias, semanas de viagem podem se acumular para que essa sonhada mobilidade consiga se efetivar. Depois disso, anos se acumulam antes de poderem retornar ou emigrar para outro país.

Todos esses fatores denotam como não é a suposta leveza de um mundo "globalizado e interconectado" que cria essa mobilidade. Sua causa continua sendo o peso da busca por trabalho, com sacrifícios, custos e entraves implicados: o endividamento, a distância de familiares, a restrição dos vistos, a imobilidade que se impõe posteriormente.

Por ter que se apoiar na chance de mudar uma vida que não suporta mais, esse imigrante dificilmente renuncia sem antes tentar todas as alternativas que estão ao seu alcance. Todos esses riscos são encarados por eles como relativos, diante das relações de força que enfrentam em seus países de origem e da chance, mesmo mínima, de mudar essa vida que, em razão da sua condição de classe, passa impreterivelmente pelo fato de conseguir um trabalho. Também é verdade que, em alguns casos, embora tenham trabalho em seus próprios países, muitas vezes dizem não a uma vida marcada pela violência de diferentes tipos, que modela a estrutura social do conjunto das sociedades periféricas, atingindo em particular suas frações mais pobres.

Além de não ter a proteção da família ou uma rede de contatos consolidada, esse imigrante, no Brasil, sobretudo quando indocumentado, não conta inicialmente com nenhuma garantia de direitos sociais ou de instituições que o representem em sua condição de trabalhador. A relação dos sindicatos com os imigrantes periféricos ainda não foi estudada na profundidade que esse tema mereceria, mas sem dúvida há um distanciamento dos sindicatos dentro e fora do lugar de trabalho, ou seja, essa entidade não é uma referência de apoio, como costumava ser para os imigrantes no passado ${ }^{14}$.

\footnotetext{
${ }^{14}$ É claro que essa problemática não se explica por nenhuma apatia política desses imigrantes, que não é uma verdade de fato, pois se exprimem em diferentes espaços de luta, inclusive na esfera do trabalho. Se essa aproximação não ocorreu, o motivo deve ser buscado na crise de representação sindical, que é internacional e envolve também os próprios brasileiros, conforme diversos estudos sociológicos críticos têm indicado, também apontando suas raízes mais profundas no próprio sistema econômico vigente e nos
} 
Ao contrário do distanciamento dos imigrantes em relação aos sindicatos, o estudo de Santos (2014) faz transparecer a existência de uma disputa de forças para canalizar seus espaços de organização política e cultural, por parte de entidades religiosas, partidos políticos e organizações não governamentais. Como a comunidade boliviana representa uma das principais nacionalidades de estrangeiros na cidade de São Paulo, com muitos já naturalizados e outros potenciais futuros eleitores (por nascimento, casamento ou paternidade em solo nacional), representa o principal alvo dessa "cooptação", notadamente pelos partidos políticos. Entretanto, o autor mostra que há igualmente ações coletivas mais independentes por parte desses imigrantes. Nesse sentido, conforme destaca, as diferentes associações de caráter cultural têm um papel potencialmente político não desprezível.

Outro aspecto que não pode ser ignorado refere-se ao choque de sentir uma realidade periférica se recolocar, às vezes mais brandamente do que em seus próprios países, porém ainda dura. Os imigrantes sentem esse impacto de imediato (principalmente os que se destinam para grandes metrópoles como São Paulo e Rio de Janeiro), pois partem com a ilusão de encontrar um país em pleno desenvolvimento, que ofereceria trabalho e seria mais acolhedor em relação às suas "antigas" metrópoles, onde sabem que as portas da imigração e refúgio estão teoricamente fechadas.

De imediato, o deslocamento internacional os faz entender que, apesar da imagem, o Brasil continua sendo um país da periferia do capitalismo, ou seja, o trabalho aqui é pesado e vale pouco. Mas, a despeito disso, ainda é uma via para se buscar melhores condições de vida em relação àquelas encontradas no país de origem.

Embora o salário possibilite pequenas vantagens de compra no próprio país, facilitadas pela taxa de câmbio do real em relação a muitas outras moedas periféricas - o que não deixa de representar um reflexo da "hierarquia das moedas" (DE CONTI, 2011) mesmo entre países periféricos -, no fundo, ainda permanece nesses imigrantes um resquício de esperança de que, nos países centrais, a realização do projeto imigratório seria diferente. De fato, o "Norte" ainda continua sendo o horizonte desses imigrantes,

diversos mecanismos de pressão sobre o trabalho (ANTUNES \& SANTANA, 2014). Mas também é verdade, como evidencia Basso (2004), que a atitude dos sindicatos com relação aos imigrantes internacionais é "no mínimo, ambígua", pois em alguns casos tende a reforçar a divisão entre trabalhadores com base na defesa de sentimentos racistas e nacionalistas, mais do que enxergar a luta comum e as potencialidades desse encontro. Contudo, o autor não deixa de lembrar a importância do espaço de lutas dos sindicatos, tendo em vista que, em alguns casos, também representam um ambiente que preserva e cultiva a perspectiva internacionalista. 
mesmo se, na realidade, poucos consigam empreender a segunda etapa migratória e a maioria tenha que "se resignar" a viver nas periferias.

É claro que o tempo de permanência no Brasil pode possibilitar uma melhor estruturação, mas não é garantia de melhores remunerações no trabalho - tampouco a regularização dos documentos ou o aprendizado do português. Com acesso restrito a empregos que ofereçam melhores salários e condições de trabalho, esses imigrantes possuindo ou não um título universitário e/ou experiências de trabalho consideradas qualificadas - estão em relação direta com atividades laborais de baixa remuneração (geralmente de um a dois salários mínimos), muitas vezes informais e desprotegidas legalmente, em particular intensas em horas e sobrecarga de trabalho. Há muitos casos de imigrantes periféricos que, não obstante possuírem títulos universitários, só conseguem se inserir em postos que não exigem qualificação. Do mesmo modo, há trabalhos que desenvolvem, por exemplo, na costura ou doméstico, que requerem muitos conhecimentos apesar de não serem reconhecidos enquanto parâmetros de "qualificação" e melhores salários.

Fatores, portanto, problemáticos, que poderiam ser contrastados com outras experiências de imigrantes que conquistaram condições melhores de trabalho e de estruturação social, principalmente dos grupos radicados há mais tempo no país. A importância de contrabalancear essas experiências laborais relaciona-se com uma perspectiva que evita "vitimizar" os imigrantes e ilumina suas próprias iniciativas e respostas a condições adversas. No entanto, é preciso ter cautela para não transformar casos isolados em regra ao se falar de experiências de trabalho essencialmente coletivas, que não envolvem uma nacionalidade exclusiva, e são condicionadas pelo funcionamento de atividades econômicas. Não é por acaso que quadros muitos similares de condições precárias de trabalho de bolivianos, peruanos e paraguaios são verificados na Argentina ou no Chile, países para os quais também se destinam, desde as últimas décadas, muitos imigrantes intrarregionais e agora também começam a atrair aqueles de países periféricos de outros continentes (BENENCIA \& QUARANTA, 2006; REYES, 2012).

Há uma exposição, o que não é sinônimo de aceitação passiva, a diversificados mecanismos de abusos e exploração, no trabalho e na vida social, que atingem dimensões redobradas para aqueles em situação indocumentada, e extremas, se levados em consideração o trabalho análogo à escravidão e o tráfico de humanos.

\section{Considerações finais}


Se a presença dos periféricos na periferia era, de alguma forma, mais "tolerada" na última década, quando o mercado de trabalho brasileiro estava aquecido; a partir de agora (2015), com o brusco aumento das taxas de desemprego, passa a simbolizar concretamente o pretenso "roubo" de postos de trabalho, mesmo daqueles mais explorados, os quais os trabalhadores nacionais, se pudessem, deixariam de almejar.

O percurso expositivo aqui apresentado teve como fim oferecer elementos que ajudam na compreensão das razões pelas quais, mesmo com o percentual baixíssimo da população estrangeira na atualidade do país - o que afasta, por enquanto, a consideração de grandes impactos no funcionamento do mercado de trabalho doméstico - a figura do imigrante e do refugiado continua, como no passado, a representar uma "ameaça" ao emprego, portanto também um potencial alvo de agressões de diferentes tipos.

A especial ênfase dada à dimensão do trabalho se justifica por elucidar questões de fundo que não podem ser ignoradas para se compreender esses fenômenos. Além disso, procurou-se trazer em discussão as características históricas de uma "outra" base social da imigração no país, que começa a se manifestar no final da década de 1960, se diversificando e ganhando intensidade despois da eclosão da crise, em 2007.

Para concluir, é necessário lembrar que a demanda pela força de trabalho imigrante nunca deixou e nem deixará de existir no Brasil, por ser estratégica e estrutural ao funcionamento do mercado de trabalho, ou seja, a crise não fará com que os imigrantes e refugiados deixem de vir ao país ${ }^{15}$. Além disso, o Brasil não está separado do já referido cenário internacional, no qual se anuncia uma intensificação desses fluxos no futuro (ACNUR, 2014; ONU, 2013).

Ao mesmo tempo em que os Estados-nação, e parte de suas sociedades, devem negar a presença desses imigrantes, a solução colocada para o funcionamento do mercado de trabalho em muitos países, que de forma alguma pode renunciar a essa força de trabalho, é a de que permaneçam e trabalhem, desde que indocumentados, ou seja, escondidos, de forma subterrânea, legalmente desprotegida, portanto superexplorados (CHOMSKY, 2014; BERGGREN et al., 2007).

Mesmo porque o retorno não se colocou como uma solução viável para a maioria desses imigrantes no recente crise e desemprego nos países centrais. Do mesmo modo, a despeito de os efeitos dessa crise na periferia do capitalismo sempre se colocarem de forma socialmente mais perversa, estão impossibilitados de voltar aos países de origem,

\footnotetext{
15 Tal afirmação já se comprovara na década de 1980 e 1990, com relação aos bolivianos e coreanos, que se direcionavam principalmente à cidade de São Paulo para trabalhar na indústria têxtil (Silva, 2008).
} 
em função das relações de força que expulsam esses grandes contingentes populacionais na atualidade (SASSEN, 2014; BASSO, 2003).

E mesmo se se apresentasse como uma alternativa, os periféricos na periferia conhecem bem as dificuldades de se migrar internacionalmente nos dias de hoje, em função das barreiras das políticas imigratórias, em particular quando se fala da autorização de trabalho em território estrangeiro.

O desafio de pesquisas está colocado, no sentido de se compreender o que significa ser um periférico na periferia, agora num contexto de uma crise - por sinal, considerada, por alguns especialistas, como uma das mais graves da história do sistema capitalista - e suas dinâmicas particulares de manifestação nos países periféricos.

Como ponto de partida, é importante perceber que muitas questões antigas da história da imigração no Brasil, agora, se recolocarão a partir de "outra" base social, em diferentes modalidades dos movimentos migratórios. E vale igualmente lembrar que essa história é composta de tensões, mas também de aproximações entre "nacionais" e estrangeiros".

\section{Bibliografia}

ALTO COMISSARIADO DAS NAÇÕES UNIDAS PARA REFUGIADOS, Asylums Trends 2014. Levels and trends in industrialised countries, Geneva, 2015.

Refúgio no Brasil: uma análise estatística (janeiro de 2010 a outubro de 2014), Brasília, 2014.

ANTUNES, R. (Org.). Riqueza e miséria do trabalho no Brasil II, São Paulo: Boitempo, 2014.

ANTUNES, R.; SANTANA, M. A. The dilemas of the New Unionism in Brazil: Breakes and continuities, Latin American perspectives, v. 1, 2014, p. 10-21.

BAENINGER, R. Migrações contemporâneas no Brasil: desafio para as políticas sociais. In: PRADO, E. J. P.; COELHO, R. Migrações e trabalho. Brasília: Ministério Público do Trabalho, 2015.

(Org.). Altas Temático: Observatório das Migrações em São Paulo. Campinas: NEPO/UNICAMP, 2013.

BAENINGER, R.; SIMAI, S. Racismo e sua negação: o caso dos imigrantes bolivianos em São Paulo. Travessia, Ano XXIV, n. 68, 2011.

BAENINGER, R.; ANTICO, C. Questões decorrentes da emergência da migração internacional no Brasil. In: PROGRAMA INSTITUCIONAL DE AVALIAÇÃO E ACOMPANHAMENTO DAS MIGRAÇÕES INTERNACIONAIS NO BRASIL CONTEMPORÂNEO, Migrações internacionais: herança XX, agenda XXI, Campinas: FNUAP, vol. 2, 1996. 
BASSANEZI, M. S. C. B. Imigrações internacionais no Brasil: um panorama histórico. In: PATARRA, N. (Org.). Emigração e Imigração Internacionais no Brasil Contemporâneo. São Paulo: FNUP, 1995.

BASSO, P. Racismo de Estado e antirracismo de classe. Margem Esquerda, v. 24, 2015, p. 57-71.

L'ascesa del razzismo nella crisi globale. In: BASSO, Pietro (Org.). Razzismo di stato: Stati Uniti, Europa, Italia. Milano: FrancoAngeli, 2010.

Sul rapporto tra immigrati e sindacati. In: MAURI, L.; VISCONTI, L. Diversity management e società multiculturale: teorie e prassi. Milano: FrancoAngeli, 2004.

Sviluppo diseguale, migrazioni, politiche migratorie. BASSO, P.; PEROCCO, F. (Orgs.) Gli immigrati in Europa: Diseguaglianze, razzismo, lotte. Milano: FrancoAngeli, 2003.

BENENCIA, R.; QUARANTA, G. Mercados de trabajo y economías de enclave: La "escalera boliviana" en la actualidad. Estudios Migratorios Latinoamericanos, v. 20, n. 60, 2006, p. 413-432.

BERGGREN, E.; LIKIC-BRBORIC; B.; TOKSOZ, G.; TRIMIKLINIOTIS, N. Irregular Migration, Informal Labour and Community: A Challenge for Europe. Maastricht: Sharker Publishing: 2007.

BRAGA, R. A política do precariado: do populismo à hegemonia lulista. São Paulo: Boitempo, 2012.

CARNEIRO, M. T. C.; FRANZINA, E.; CROCI, F. (Orgs.). História do Trabalho e Histórias da Imigração. São Paulo: Edusp, 2010.

CHOMSKY, A. Undocumented: how immigration became illegal. Boston: Beacon Press, 2014.

DE CONTI, B. M., Políticas cambial e monetária: os dilemas enfrentados por países emissores de moedas periféricas, Tese de Doutorado, Universidade Estadual de Campinas e Université Paris 13, Campinas-Paris, 2011.

DREHER, S. Neoliberalism and Migration: An Inquiry into the politics of globalization. Hamburg: LIT Verlag, 2007.

FERNANDES, D.; CASTRO, M. C. G. Estudo sobre a migração haitiana ao Brasil e diálogo bilateral. Belo Horizonte: Pontifícia Universidade Católica, 2014.

FERNANDES, F. A integração do negro na sociedade de classes: o legado da "raça branca" (Vol. 1 e 2). São Paulo: Globo, (1964) 2008 a.

A revolução burguesa no Brasil. São Paulo: Globo, (1975) 2008 b.

FIGUEIRA. R. R.; PRADO, A. A. Olhares sobre a escravidão contemporânea: novas contribuições críticas. Rio de Janeiro de Janeiro: Mauad, 2011.

GERALDO, E. O "perigo alienígena": política imigratória e pensamento racial no governo Vargas (1930-1945). Tese de doutorado, Universidade Estadual de Campinas, 2007.

KREIN, J. D. As relações de trabalho na era do neoliberalismo no Brasil. São Paulo: LTR, 2013. 
LÖWY, M. Franz Kafka: sonhador insubmisso. Rio de Janeiro: Azougue, 2005.

MACKAY, S. The commanalities of experience: refugees and recent migrants. In: MACKAY, S. (Org.) Refugees, Recent Migrants and Employment: Challenging Barriers and Exploring Pathways. New York\&London: Routeledge, 2008.

MOREIRA, J. B. Política em relação aos refugiados no Brasil (1947-2010). Tese de Doutorado, Universidade de Campinas, Campinas, 2012.

REYES, A. A.; ÁLVAREZ, C. Juventud, migración y discriminación en el Chile contemporáneo. Ultima Decada, ano 20, n. 36, jul., 2012.

SASSEN, S. Brutality and Complexity in the Global Economy. Cambridge, Massachusetts: Harvard College, 2014.

SANTOS, W. A reinvenção do folclore boliviano em São Paulo, Dissertação (Mestrado), Universidade Estadual de Campinas, Campinas, 2015.

SAYAD, A. A imigração ou os paradoxos da alteridade. São Paulo: Edusp, 1998.

SEGUY, F. A catástrofe de janeiro de 2010, a "internacional comunitária" e a recolonização do Haiti, Tese de Doutorado, Universidade Estadual de Campinas, 2015.

SILVA, C. F. Trabalho informal e redes de subcontratação: dinâmicas urbanas da indústria de confecções em São Paulo, Dissertação de Mestrado, Universidade de São Paulo, São Paulo, 2008.

UNITED NATIONS, The number of international migrants worldwide reaches 232 million, Population Facts, n. 20, sep., 2013.

VILLEN, P. Imigração na modernização dependente: "braços civilizatórios" e a atual configuração polarizada, Tese de Doutorado, Universidade Estadual de Campinas, 2015. 


\section{Para citar essa obra:}

VILLEN, P. O estigma da ameaça ao emprego pelos periféricos na periferia: crise e imigração no Brasil In: RUA [online]. nº 21. Volume 1, p. 247 - 264 - ISSN 1413-2109. Novembro/2015. Consultada no Portal Labeurb - Revista do Laboratório de Estudos Urbanos do Núcleo de Desenvolvimento da Criatividade.

http://www.labeurb.unicamp.br/rua/

Capa: Disponível: http://www.portaldeangola.com/2013/12/consul-geral-de-angola-emniari-republica-do-congo-preocupado-com-adulteracao-de-emissao-de-cartoes-consulares/

Laboratório de Estudos Urbanos - LABEURB

Núcleo de Desenvolvimento da Criatividade - NUDECRI

Universidade Estadual de Campinas - UNICAMP

http://www.labeurb.unicamp.br/

Endereço:

LABEURB - LABORATÓRIO DE ESTUDOS URBANOS

UNICAMP/COCEN / NUDECRI

CAIXA POSTAL 6166

Campinas/SP - Brasil

CEP 13083-892

Fone/ Fax: (19) 3521-7900

Contato: http://www.labeurb.unicamp.br/contato 